\title{
越南杨晖矿巷道交叉点针杆支护数值分析
}

\section{Numerical Analysis of Bolt Support at Roadway Intersection in Yanghui Mine, Vietnam 陈文功 李鹏飞}

\author{
Wengong Chen Pengfei Li
}

\section{辽宁工程技术大学 矿业学院}

中国·辽宁 阜新 123000

College of Mining, Liaoning Technical University, Fuxin, Liaoning, 123000, China
【摘要】巷道交叉点处围岩应力复杂, 在越南杨晖矿巷道交叉点一直采用 $U$ 型钢支护, 但 面临很多问题, 如通风受阻、通过能力受限, 论文采用 FLAC3D 数值模拟软件, 依据杨晖矿 现场资料, 模拟 $U$ 型钢支护效果和针杆支护效果, 比较顶底板和两帮变形量, 研究结果表 明,针杆支护可以应用该矿巷道交叉处,改进该矿的支护情况。

【Abstract】The stress of surrounding rock at roadway intersection is complex. U-shaped steel support has been used at roadway intersection of Yanghui mine in Vietnam, but there are many problems, such as blocked ventilation and limited passing capacity. In this paper, FLAC 3D numerical simulation software is used to simulate the support effect of $U$-shaped steel and bolt based on the field data of Yanghui mine. The deformation of roof, floor and two sides are compared. The results show that bolt support is effective. The protection can be applied to the intersection of roadways in the mine to improve the support situation.

【关键词】交叉点; 数值模拟; 越南杨晖矿

【Keywords】roadway intersection; numerical simulation; Yanghui mine Vietnam 【DOI】10.36012/etr.v2i2.1128

\section{1 引言}

巷道交岔点是指矿井中巷道交会或分岔处的一段巷道, 该处因受两条或多条相交巷道的影响, 围岩松软破碎, 巷道跨 度和顶板悬露面积大, 加上交岔点附近巷道围岩应力变化的 叠加影响,使交岔点处围岩应力复杂。普通 $\mathrm{U}$ 型钢架棚支护目 前可以起到支护作用, 但与针杆支护相比有很多弊端, 此时针 杆支护作为一种特殊的支护方法，在技术、经济、安全方面相 较普通 $U$ 型钢架棚支护方式具有独特的优势[1]。中国学者已 对巷道交叉点进行了大量的研究。史天生 ${ }^{[2]}$ 等在定义巷道交
岔点和简述 12 种形式的基础上, 重点论述巷道交岔点在施工 过程中两条交接巷道的顶板卸载区，两帮支承压力和交岔点 拐角岩柱中支承压力的形成机理，分析采准巷道交贫点两个 地压显现阶段的特征, 提出用针杆加固围岩防止岩体丧失连 续性和稳定性的变形, 井列举了交岔点支架上荷载和侧压的 计算公式。匡忠祥等 ${ }^{[3]}$ 对采准巷道交叉点围岩受力状态进行 了三维数值模拟，揭示了巷道和巷道交叉点开挖后围岩的应 力、应变分布特征及规律。刘艳章 ${ }^{[4]}$ 等运用 FLAC3D 进行三维 数值模拟计算未支护与 4 种支护方案下巷道周壁的围岩平均 应力集中系数, 通过对比分析, 确定最优的交叉巷道针杆支护 
参数。王成 $[5]$ 等运用 FLAC3D 数值模拟软件对巷道交岔点处 加固补强前后的应力分布状态进行了模拟, 给出具体的加固 补强的支护参数。何富连回等采用 FLAC3D 数值模拟软件分 析空间交叉巷道的应力分布特点以及沿下方巷道轴向方向形 成的应力增高和降低区。比较不同方案在应力增高区内的支 护效果, 确定最终空间交叉巷道支护方案。结合现场条件设 计具体的加固补强的支护参数, 并在实践中取得较好效果。 曹日红 ${ }^{[7}$ 等利用 FLAC3D 软件对 5 种不同交叉角度的交叉巷 道交叉段围岩的应力和位移的分布特征及规律进行数值模拟 和分析，探讨不同交叉角度的交叉巷道交叉段的围岩变形情 况，从宏观角度掲示不同交叉角度的巷道交叉段围岩变形规 律，为交叉巷道施工和巷道交叉段的支护设计提供有效地参 考依据。

基于以上成果, 研究运用 FLAC3D 对越南杨晖矿埋深 $300 \mathrm{~m}$ 左右的一个巷道交叉点进行数值模拟, 交叉点直接顶为 $18.6 \mathrm{~m}$ 厚的粉砂岩, 老顶为 $42.3 \mathrm{~m}$ 厚的细砂岩, 煤层厚度是 $3.8 \mathrm{~m}$, 直接底为 $14 \mathrm{~m}$ 的粉砂岩, 老底为 $6.9 \mathrm{~m}$ 厚的中细砂岩, 这种大厚度的顶底板比较特殊, 通过针杆支护的数值模拟与 $\mathrm{U}$ 型钢架棚支护的数值模拟做对比, 比较应力和位移的变化 情况, 分析验证针杆支护可以达到或优于 $\mathrm{U}$ 型钢架棚支护的 支护效果, 使针杆支护运用在该矿巷道交叉点处,发挥针杆支 护在技术、经济、安全方面的优势, 促进该矿实现高产高效和 机械化采煤。

\section{2 工程概况}

杨晖煤矿位于越南广宁省锦谱市杨晖坊, 矿井位置如图 1 所示，模拟巷道位于该矿 14 煤层，巷道交岔口位置如图 2 所示, 14 煤层标高从 $-100 \mathrm{~m}$ 到 $-150 \mathrm{~m}$, 地质构造较简单, 无断 层经过。根据矿井开采情况以及煤层赋存条件, 下山斜井从一 $100 \mathrm{~m}$ 标高水平的 14 层轨道大巷沿煤层顶板延深到 $-150 \mathrm{~m}$ 标 高水平, 在 $-130 \mathrm{~m}$ 标高水平要开挖一条运输巷造成交岔点, 交 叉点位置如图 2 所示。地面标高水平在 $+190 \mathrm{~m}$ 左右, 交岔点距 地面 $330 \mathrm{~m}$ 左右。围岩以粉砂岩为主, 顶底板岩性如图 3 所示。

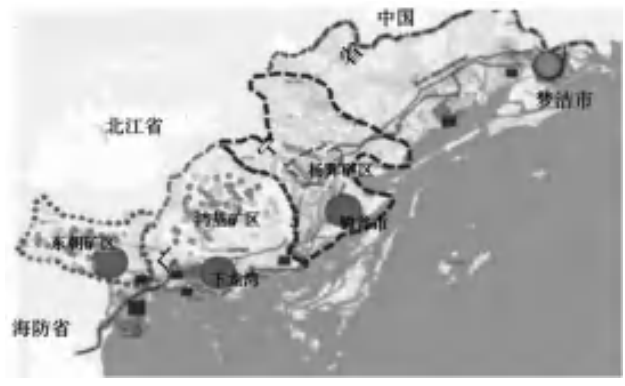

图 1 杨晖矿区位置图

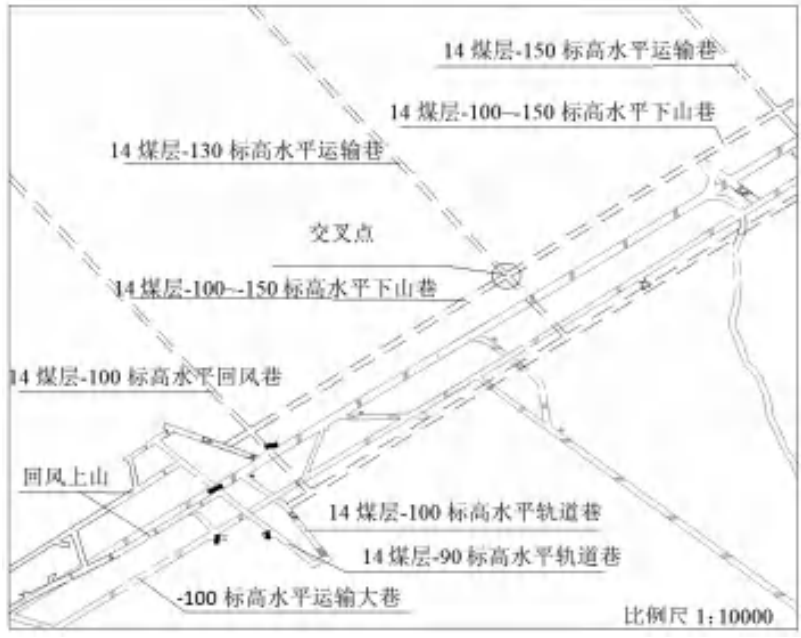

图 2 巷道交叉口位置图

目前, 该矿巷道的交岔点常选用 $U$ 型钢支架和工字钢联 合支护,在压力大、围岩变形量大的井巷中采用 $U$ 型钢可缩 性支架支护。但在使用过程中, 无论是采用 $U$ 型钢支架支护, 还是采用工字钢支架支护, 都存在一定的弊端。采用 $U$ 型钢 支架支护时，交岔点支巷的巷道断面受 $\mathrm{U}$ 型钢梁弧的影响， 会减小 $1 \sim 3 \mathrm{~m}^{2}$, 影响正常通风、运输、行人等; 采用工字钢支架 支护时, 支架整体性较差、支架不稳定, 特别是当发生水灾时, 交岔点支架易被冲垮塌落, 巷道易冒顶, 缺乏抗灾能力。 $U$ 型 钢支护断面图如图 4 所示。

\begin{tabular}{|c|c|c|c|c|}
\hline $\begin{array}{l}4,12 \\
8 \%\end{array}$ & Htix & 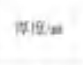 & 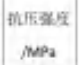 & 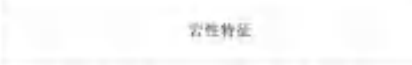 \\
\hline Eevit & & 16 & 4.5 & 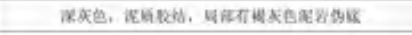 \\
\hline tare & & 423 & 38.5 & 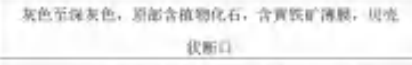 \\
\hline 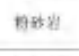 & & $\frac{15.22 .36}{18.6}$ & 4.5 & 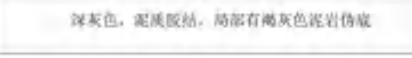 \\
\hline 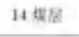 & & $\frac{0276.36}{3.31}$ & 148 & 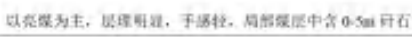 \\
\hline EDEZ & & $\frac{0.273}{38}$ & 4.5 & 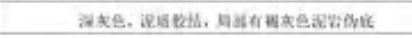 \\
\hline 中证的 & & $\frac{a 15,2}{7 \hbar}$ & 665 & 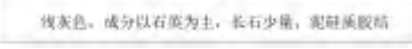 \\
\hline
\end{tabular}

图 3 岩层综合柱状图

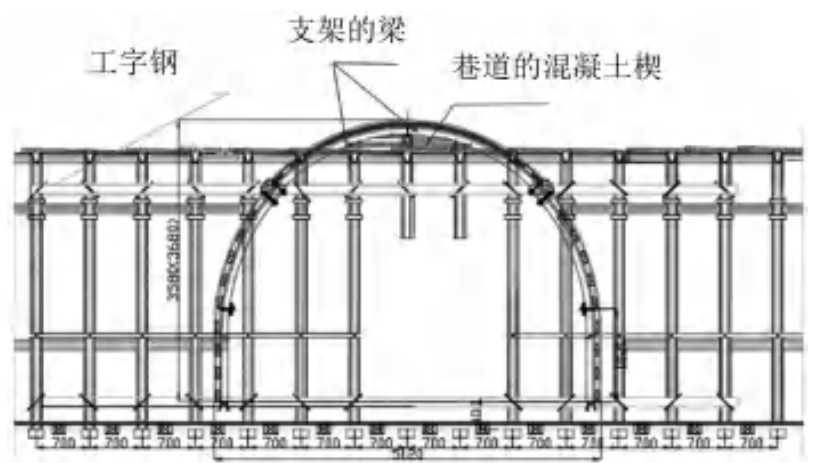

图 $4 \mathrm{U}$ 型钢支护巷道断面图

针杆支护是一种有效的采准巷道支护方式，可以对巷道 围岩的强度起强化作用,显著提高围岩的稳定性,而且支护成 


\section{工程施工技术 Engineering Construction Technology}

本低、成巷速度快、劳动强度低、提高巷道断面利用率高、简化回 采面端头维护工艺简单、作业环境和安全生产条件好等优点。目 前已从中国引进针杆支护技术, 成功应用于回采巷道, 但是还没 有应用到交叉路口。因此, 巷道交贫点锚杆组合支护技术有着极 其重要的意义。该矿目前支护方案变形量如表 1 所示。

表 1 原始支护方案围岩变形量

\begin{tabular}{c|c|c|c|c}
\hline 支护方案 & $\begin{array}{c}\text { 顶板下沉量 } \\
/ \mathrm{mm}\end{array}$ & $\begin{array}{c}\text { 底鼓量 } \\
/ \mathrm{mm}\end{array}$ & $\begin{array}{c}\text { 右帮位移量 } \\
/ \mathrm{mm}\end{array}$ & $\begin{array}{c}\text { 左帮位移量 } \\
/ \mathrm{mm}\end{array}$ \\
\hline $\mathrm{U}$ 型钢 & 318.0 & 245.8 & 254.6 & 254.9 \\
\hline $\begin{array}{c}\mathrm{U} \text { 型钢、工字 } \\
\text { 钢联合支护 }\end{array}$ & 298.7 & 245.0 & 240.8 & 240.8 \\
\hline
\end{tabular}

\section{3 交叉巷道支护优化分析}

\section{1 交叉巷道模型构建}

模拟采用数值模拟的方法, 运用 FLAC3D 5.0 有限差分 软件, 选择摩尔-库伦 $(\mathrm{M}-\mathrm{C})$ 准则, 根据该矿现有的力学实验 数据, 计算采用的巷道围岩力学参数见表 2 。

\section{表 2 巷道围岩参数}

\begin{tabular}{c|c|c|c|c|c|c}
\hline 岩性 & $\begin{array}{c}\text { 体积模量 } \\
/ \mathrm{GPa}\end{array}$ & $\begin{array}{c}\text { 剪切模量 } \\
/ \mathrm{GPa}\end{array}$ & $\begin{array}{c}\text { 密度 } \\
/ \mathrm{N} . \mathrm{m}\end{array}$ & $\begin{array}{c}\text { 秥聚力 } \\
/ \mathrm{MPa}\end{array}$ & $\begin{array}{c}\text { 内摩 } \\
\text { 擦角 }\left({ }^{\circ}\right)\end{array}$ & $\begin{array}{c}\text { 抗拉强度 } \\
/ \mathrm{MPa}\end{array}$ \\
\hline 粉砂岩 & 32 & 19 & 2510 & 7 & 42 & 3.3 \\
\hline 煤 & 8 & 2 & 1310 & 2 & 36 & 1.4 \\
\hline 细砂岩 & 25 & 15 & 2500 & 6 & 42 & 3.6 \\
\hline
\end{tabular}

由于受力具有对称性，所以选取交叉巷道的 $1 / 4$ 建立模 型, 模型长 $\times$ 宽 $\times$ 高为 $20 \mathrm{~m} \times 20 \mathrm{~m} \times 40 \mathrm{~m}$, 如图 5 所示, 针杆安装 立体图如图 6 所示,针杆安装平面图如图 7 所示。

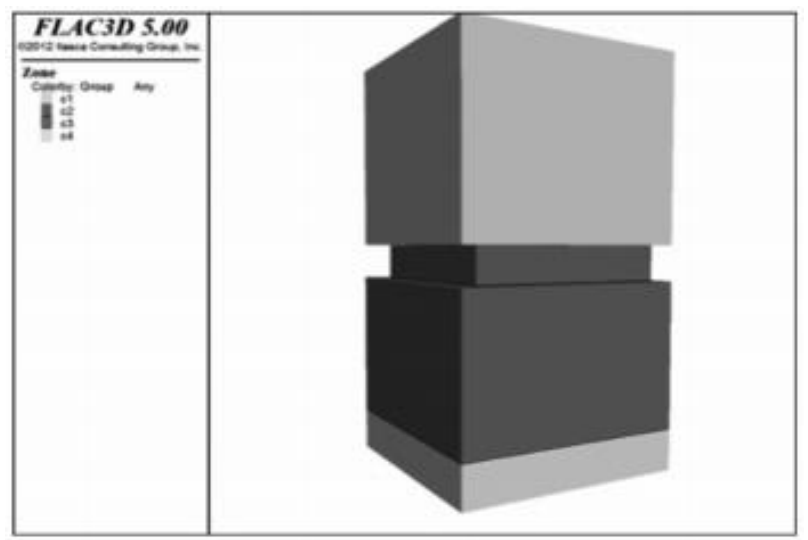

图 5 三维数值模拟图

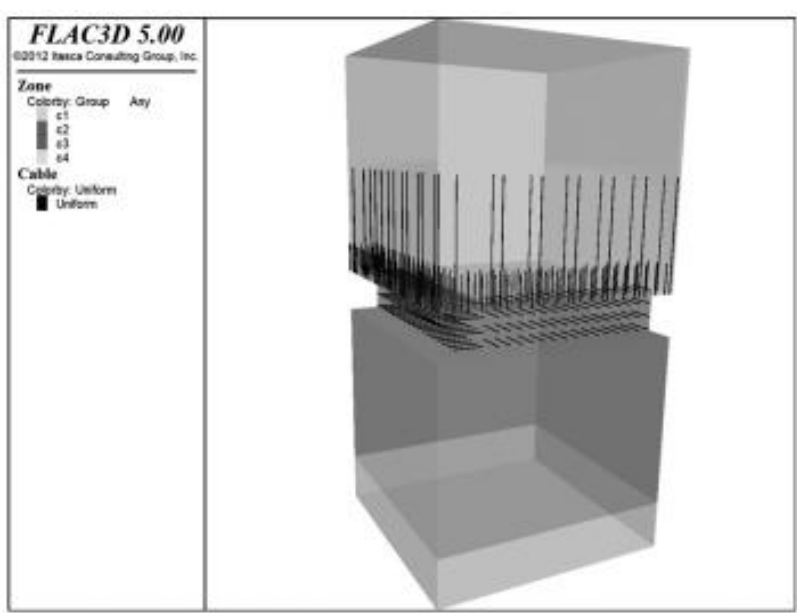

图 6 针杆安装位置图

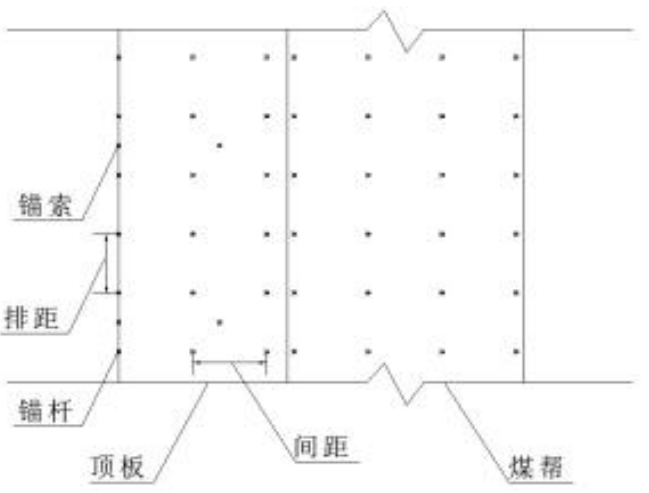

图 7 针杆安装平面图

通过比较顶板下沉量以及煤帮变形量的大小来验证针杆 与 $\mathrm{U}$ 型钢支架的支护效果。

实验巷道埋深为 $337.2 \mathrm{~m}$ 。所以模型上边界施加的垂直方 向载荷为 $-7.9 \mathrm{MPa}$, 前后左右下 5 个面采用位移约束, 限制法 方向运动。开挖巷道为矩形巷道, 宽 $5.0 \mathrm{~m}$ 高 $3.5 \mathrm{~m}$ 。

\section{2 支护方案及效果}

建立模型先无支护进行计算, 由于模拟与实际有差距, 按 一定的比例改岩石力学参数,使变形接近现场实际变形。变形 结果如图 8 所示。

运用软件内置的命令找到巷道顶底板和两帮的支撑力, 越南现场运用的架棚支护的效果用 $5 \%$ 的原支撑力进行模 拟, 模拟结果如图 9 所示; 针杆支护的效果先用 $70 \%$ 的原支 撑力进行计算, 达到平衡后添加针杆针索, 依据刘艳章等《确 定交叉巷道针杆支护参数的围岩平均应力集中系数分析方 法》得出的结论, 选择现有针杆长 $2.4 \mathrm{~m}$ 设置间距为 $1.1 \mathrm{~m}$, 排 距为 $1.0 \mathrm{~m}$, 每排 5 根针杆, 针索长 $9.0 \mathrm{~m}$, 间距 $1.5 \mathrm{~m}$ 排距为 $3.3 \mathrm{~m}$, 每排 3 根锚索, 锚杆锚索均采用端锚的针固方式, 针杆 针固长度为 $1.3 \mathrm{~m}$, 针索针固长度为 $1.7 \mathrm{~m}^{[8]}$ 。然后去掉巷道周围 


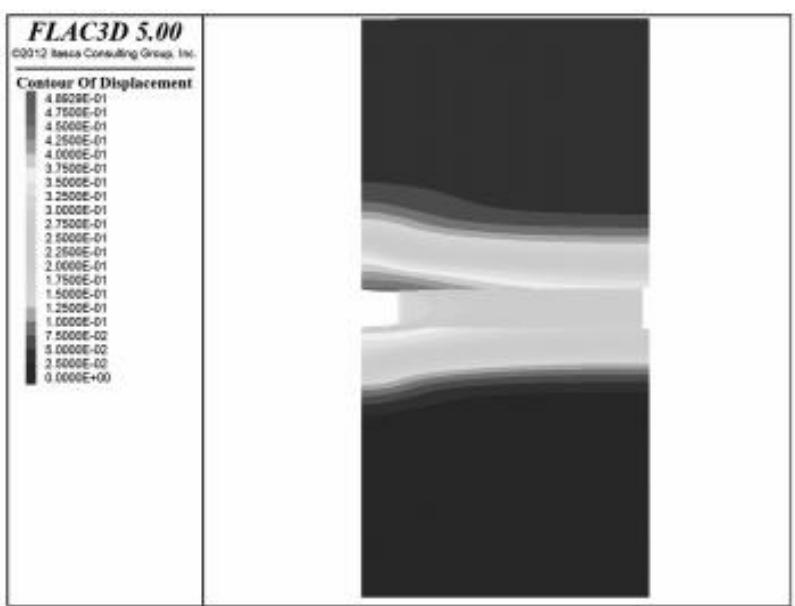

图 8 未支护巷道围岩变形量

所有的支撑力再进行计算, 计算结果如图 10 所示。针杆针索 力学参数如表 3 所示。

表 3 针杆力学参数

\begin{tabular}{c|c|c|c|c|c}
\hline $\begin{array}{c}\text { 弹性模量 } \\
/ \mathrm{GPa}\end{array}$ & $\begin{array}{c}\text { 抗拉强度 } \\
/ \mathrm{MPa}\end{array}$ & $\begin{array}{c}\text { 横截面积 } \\
/ \mathrm{m}^{2}\end{array}$ & $\begin{array}{c}\text { 黍聚力 } \\
/ \mathrm{N} / \mathrm{m}\end{array}$ & $\begin{array}{c}\text { 刚度 } \\
/ \mathrm{GPa}\end{array}$ & $\begin{array}{c}\text { 预紧力 } \\
/ \mathrm{kPa}\end{array}$ \\
\hline 200 & 400 & 0.000314 & 2000 & 0.9 & 60 \\
\hline
\end{tabular}

\section{3 结果分析}

无支护的情况下交叉口处顶板下沉量最大为 $489 \mathrm{~mm}$, 两 帮变形量为 $275 \mathrm{~mm}$, 底鼓为 $375 \mathrm{~mm}$ 。按 $5 \%$ 的支撑力模拟的架 棚支护交叉口处顶板下沉量最大为 $292 \mathrm{~mm}$ ，两帮变形量为 $250 \mathrm{~mm}$, 底鼓为 $250 \mathrm{~mm}$ 。模拟的针杆支护交叉口处顶板下沉 量最大为 $175 \mathrm{~mm}$, 两帮变形最大为 $150 \mathrm{~mm}$, 底鼓为 $325 \mathrm{~mm}$ 。通 过比较结果，针杆支护在越南复杂地质条件下可以起到支护 作用,明显优于现场原始两种支护方案。

\section{4 结论}

(1)交叉口应力状态复杂, 单纯的架棚支护不能起到很好 的支护效果，应采用多种支护方式联合控制巷道围岩; 2 针杆 针索适用性较广, 在越南复杂地质情况下依然可以起到很好 的支护效果 ${ }^{[0]}$ 。

\section{参考文献}

[1]陈士军.煤巷针杆支护的实践与应用 [J].煤炭科学技术,2004 (8):32-34.

[2]史天生.巷道交岔点的围岩变形规律及支架计算方法 [J].冶金 矿山设计与建设,1994(5):7-11.

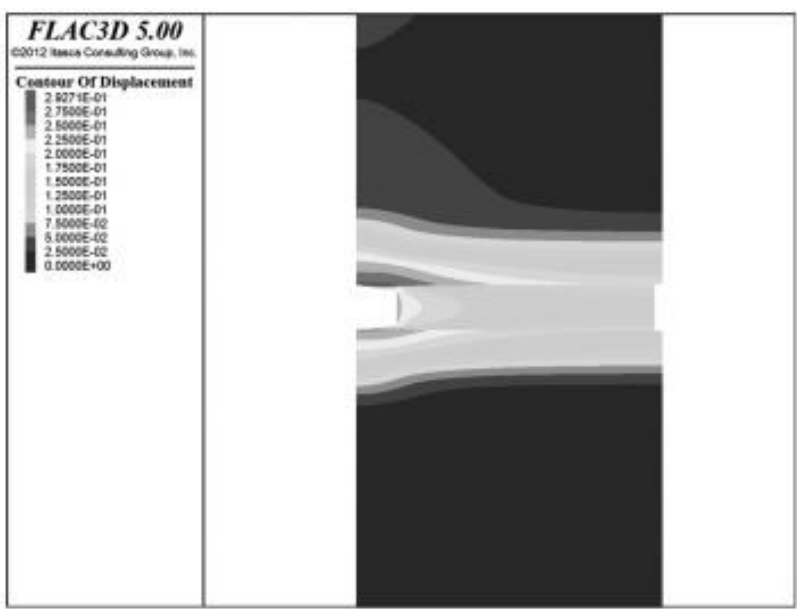

图 9 架棚支护巷道围岩变形量

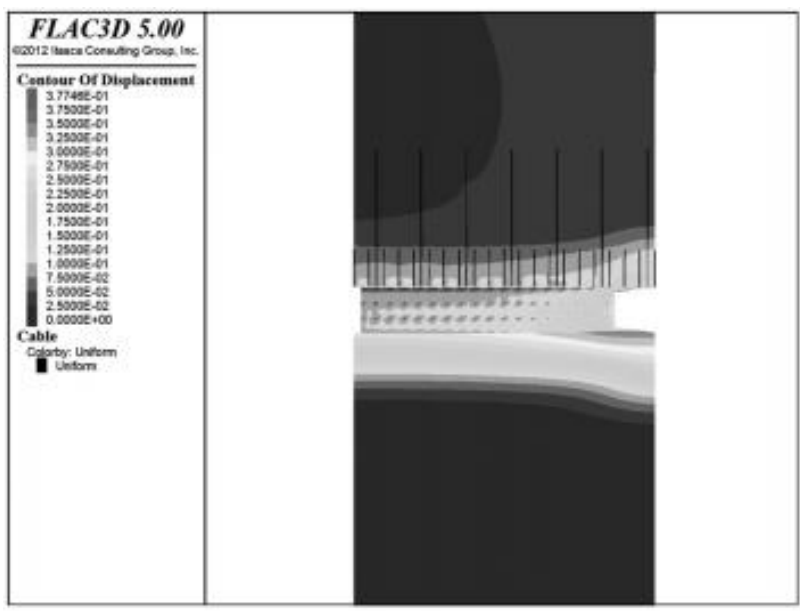

图 10 针杆支护巷道围岩变形量

[3]匡忠祥,宋卫东,邓成爱.采准巷道交岔点围岩受力状态的三维 数值模拟研究 $[\mathrm{J}]$.金属矿山,2007(9):46-49+100.

[4]刘艳章,李京,胡斌,等. 确定交叉巷道针杆支护参数的围岩平均 应力集中系数分析方法 [J].金属矿山,2018(7):32-37.

[5]王成,张农,李桂臣,等. 巷道交岔点的数值模拟分析与支护 $[\mathrm{J}]$. 采矿与安全工程学报,2008,25(4):384-388.

[6]何富连,康荣,李宏涁, 等.新三矿大断面空间近距交叉巷道数值 分析及支护[J].煤炭工程,2011(3):60-62

[7]曹日红,曹平,张科,等.考虑应变软化的巷道交叉段稳定性分析 [J].岩土力学,2013,34(6): 1760-1765+1821.

[8]赵敏.针杆针固长度对针固效果的影响研究 [D].徐州:中国矿 业大学, 2016

[9]徐建来. 软岩巷道支护稳定性及数值动态模拟研究 [D]. 阜新: 辽 宁工程技术大学,2009. 